\title{
CDISC SEND Body Weight Test Code Terminology
}

National Cancer Institute

\section{Source}

National Cancer Institute. CDISC SEND Body Weight Test Code Terminology. NCI

Thesaurus. Code C89962.

The terminology that includes concepts relevant to the Clinical Data Interchange Standards Consortium (CDISC) Standard for the Exchange of Non-clinical Data (SEND) body weight test short names. 